\title{
Levels of arsenic and mercury in human blood from Tarkwa and its environs, a mining area in Wassa West District of Ghana
}

\author{
Samlafo ${ }^{7}$, B. V.
}

\begin{abstract}
This paper examines the levels of $\mathrm{Hg}$ and As in blood samples of inhabitants of Tarkwa and its environs, a mining impacted area in contrast with the populations of Akatsi and its environs, a non-mining impacted area. Blood samples were analysed for arsenic (As) and mercury $(\mathrm{Hg})$ using instrumental neutron activation analysis. The prepared samples were irradiated at a thermal neutron flux of $5 \times 1011 \mathrm{n} \mathrm{cm}-2 \mathrm{~s}-1$ using the Ghana Research Rector-1. An independent one- tailed student t-test was used to compare the means of both the experimental and the control subjects in order to establish the statistical significant differences between the two groups. The level of probability at which significant differences existed between the groups was set at $p<0.05$ at $95 \%$ confidence level). Mercury in blood samples in the experimental subjects ranged from 0.01- 0.70 $\mu \mathrm{g} / \mathrm{mL}$, with a mean of $0.08 \mu \mathrm{g} / \mathrm{mL}$. Mercury in the control subjects ranged from 0.01$2.38 \mu \mathrm{g} / \mathrm{g}$, with a mean of $0.12 \mu \mathrm{g} / \mathrm{mL}$. Arsenic levels in blood in the experimental subjects ranged from 0.02-5.82 $\mu \mathrm{g} / \mathrm{mL}$, with a mean of $0.67 \mu \mathrm{g} / \mathrm{mL}$. Arsenic in control subjects ranged from $0.01-0.37 \mu \mathrm{g} / \mathrm{mL}$ with a mean of $0.04 \mu \mathrm{g} / \mathrm{mL}$. The measurement precision specified by the relative standard deviation was within $\pm 3 \%$. The results showed no statistical significant difference between the level of $\mathrm{Hg}$ in both the experimental and the control subjects, implying the level of $\mathrm{Hg}$ in the experimental subjects could not be attributed to the mining activities in the area. However, statistical differences were observed between the levels in the experimental samples and that of the control group $(\mathrm{p}=6.71 \times 10-6>0.05)$ implying the level observed in the experimental group could be due to the mining activities in the area.
\end{abstract}

Keywords arsenic level, mercury level, human blood, blood samples

\section{Introduction}

Artisanal or small-scale mining, using gold-mercury amalgamation to extract gold from ore, is a significant source of exposure for the workers and nearby populations (UNEP, 2002). Miners burn the gold-mercury amalgam to vaporize the mercury and recover the gold; thus the miners and local populations can have high exposure to mercury vapours. For example, mercury concentrations in air as high as $60 \mathrm{mg} / \mathrm{m} 3$ have been associated with amalgam burning at a mining site (UNIDO, 2003). In addition, metallic mercury wastes are usually dumped into or near water courses. These discharges can lead to elevated methylmercury concentrations in the fish from these water bodies as inorganic $\mathrm{Hg}$ is methylated by microorganisms into methylmercury. Consumption of these contaminated fish and water by communities resident along these rivers can result in the intake of high levels of methylmercury (UNIDO, 2003). Arsenic in the Arsenopyrite ores

\footnotetext{
${ }^{7}$ Samlafo, B. V., lectures at the Department of Chemistry Education, University of Education, Winneba. Email:
} 
Levels of arsenic and mercury in human blood from Tarkwa and its environs, a mining area in

Wassa West District of Ghana Samlafo, B. V.Samlafo, B. V.

containing the gold is also likely to find its way into the environment and hence the food chain. These pollutants are likely to get to man through the food chain.

The presence of mercury in blood indicates recent or current exposure to mercury. There is a direct relationship between mercury concentrations in human blood and consumption of fish contaminated with methylmercury (UNIDO, 2003). As described previously, methylmercury in the diet is readily absorbed through the gastrointestinal tract and distributed throughout the body by the blood. Usually blood methylmercury concentrations reach a maximum within 4 to 14 hours and undergoes clearance from the blood to other body tissues after 20 to 30 hours. The World Health Organization considers the normal mean concentration of total mercury in blood to be between 5 to 10 $\mu \mathrm{g} / \mathrm{L}$ in individuals with no consumption of contaminated fish (UNIDO, 2003). The National Research Council (NRC) of United States recommended $2 \mu \mathrm{g} / \mathrm{L}$ as the normal mean concentration for populations with little or no fish consumption in the United States (NRC, 2000).

Following exposure via ingestion, methylmercury is rapidly and extensively absorbed (about $95 \%$ ) through the gastrointestinal tract. This form of mercury is distributed throughout the body and easily penetrates the blood-brain and placental barriers. Methylmercury distributed throughout the body combines with cysteine, which is an amino acid found in most protein and appears to be mediated by the formation of a methylmercury-cysteine conjugate, which is transported into cells via a neutral amino acid carrier protein. A methylmercury-cysteine conjugate can pass through not only the blood-brain barrier but also the placenta via an amino acid transporter. Methylmercury can enter the brain where it is oxidized and accumulated and eventually causes chronic exposure and, depending on the level of exposure, can lead to adverse human health effects (Sakamoto, Kubota, Liu, Murata, Nakai \& Satoh, 2004). Some methylmercury in the body is slowly converted to inorganic mercury. Methylmercury has a relatively long biological half-life in humans; estimates range from 44 to 80 days. Excretion of methylmercury occurs primarily via the faeces, in hair, with less than one-third of the total excretion occurring through the urine. Methylmercury is also excreted through human milk but at much lower levels (LaKind, et al., 2005; WHO, 2004).

From the methylmercury poisoning episodes in Japan and Iraq, it is known that severe effects take place in the development of the brain and nervous system of the unborn child (the foetus), also, severe effects on adults were observed. The most common clinical signs observed in adults were , sensory disturbances, tremors, impairment of hearing, constriction of the visual field and difficulty in walking. Both the central and peripheral nervous systems show signs of damage (Eto, Tokunaga, Nagashima \& Takeuchi, 2002; Kinjo, Higashi, Nakano, Sakamoto \& Sakai, 1993). Deficits in acts of daily living observed in Minamata disease adult patients significantly increased and were further aggravated by aging (Fukuda, Ushijama, Kitano, Sakamoto, \& Futatsuka, 1999). Neurological subjective complaints as well as nonspecific complaints in a population in a polluted area in Minamata could also be influenced by past methylmercury exposure (Grandjean, Weihe, White, Debes, Araki, Yokoyama, Murata, Sorensen, Dahl \& Jorgensen, 1997). A few epidemiological studies(especially the Faroe Islands and New Zealand studies) have recently provided evidence that methylmercury in seafood consumed by pregnant women-even at low mercury concentrations (about10-20\% of observed effect levels on adults) — appears to have subtle, persistent effects on children's 
mental development as observed at about age 4 to 7 , i.e. so-called cognitive deficits (Grandjean, Weihe, White, Debes, Araki, Yokoyama, Murata, Sorensen, Dahl, \& Jorgensen, 1997).

Blood is the main vehicle for the transport of arsenic following absorption, and arsenic is cleared relatively rapidly from it. Transplacental transfer of arsenic appears to occur in humans. This finding is based on autopsy data and on reports showing that blood levels in the cords of neonates approximate those of their mothers (WHO, 1981). Data on the effects of valency and exposure level on the tissue distribution of arsenic indicate that levels of arsenic in the kidneys, liver, bile, brain, skeleton, skin and blood are 2-25 times higher for the trivalent than for the pentavalent form and are greatly increased at higher doses (US Environmental Protection Agency, 1984).

Trivalent inorganic arsenic is oxidized in vivo in animals and humans exposed to arsenite. The opposite reaction, the reduction of arsenate to arsenite, has also been demonstrated in mice and rabbits. Both arsenite and arsenate, after reduction to arsenite, are methylated in the liver. Both methylated species,monomethyl arsonate (MMA) and dimethylarsenate (DMA), are considered to be less toxic and bind less to tissues, and are eliminated more rapidly than the unmethylated form. An interesting feature is that only humans excrete significant amounts of MMA following exposure to inorganic arsenic. The rabbit seems to be the species most similar to humans with regard to the methylation of arsenic (US Environmental Protection Agency, 1984). In human volunteers who ingested a single oral dose of arsenic $(500 \mu \mathrm{g})$ either as sodium arsenite, MMA or DMA, the excretion rate increased in order, inorganic arsenic (In-As) $<$ MMA $<$ DMA. Assuming that methylation is the detoxifiyng mechanism for inorganic As, it has been suggested that when uptake exceeds a certain value, the methylation mechanism becomes saturated, and its efficiency declines as exposure increases.

\section{Purpose and context of study}

Several studies have examined a number of reproductive end-points in relation to arsenic exposure, and the results suggest elevations in foetal, neonatal and postnatal mortality, lowered birth weight, spontaneous abortions, stillbirths, and congenital malformations. However, there is no consistent evidence for any one particular end-point (WHO, 2001). The study sought to find out the extent to which the community is internally exposed to $\mathrm{Hg}$ and as a result of the mining activities in the area.

The study area has been described in an earlier paper (Serfor-Armah, Samlafo, \& Yeaboah, 2009). Biological monitoring carried out in the area revealed very interesting results. For example, human hair and nail samples collected from the Wassa West District in 2008 indicated a substantial $\mathrm{Hg}$ contamination compared to the control samples. The concentration of $\mathrm{Hg}$ in hair in experimental subjects ranged from (1.6520.46) $\mu \mathrm{g} / \mathrm{g}$ compared with the control which gave $0.49 \mu \mathrm{g} / \mathrm{g}$. Mercury in nail samples in the experimental subjects ranged from (0.97-31.94) $\mu \mathrm{g} / \mathrm{g}$ compared with the control subjects which recorded $0.73 \mu \mathrm{g} /$. Arsenic in hair in the experimental subjects ranged from $0.07-0.95 \mu \mathrm{g} / \mathrm{g}$ compared to the control which gave $0.08 \mu \mathrm{g} / \mathrm{g}$. While As in nail samples in the experimental group ranged from 0.08-3.90 $\mu \mathrm{g} / \mathrm{g}$ compared to the control which gave $0.08 \mu \mathrm{g} / \mathrm{g}$ (Serfor-Armah, Samlafo, \& Yeaboah, 2009). Other studies reported higher levels of $\mathrm{As}$ and $\mathrm{Hg}$ in environmental samples (Water, soil and sediments). 
Levels of arsenic and mercury in human blood from Tarkwa and its environs, a mining area in

Wassa West District of Ghana Samlafo, B. V.Samlafo, B. V.

\section{Methodology and experimental work}

Sampling: All the blood samples were collected in tubes already containing ethylenediaminetetraacetic acid (EDTA) as an anticoagulant. An authorization was granted by the Ghana Health Service to collect the blood samples from its health centres. The blood samples were collected from the subjects at random on two occasions from, Tarkwa Government Hospital, ABA Goldfields Hospital, Ami Maternity Home, GAG Hospital-Iduapiem, Ghana Manganese Company Hospital (GMC) - Nsuta, Pentecost clinic and coded $\mathrm{Bn}(\mathrm{n}=1-115)$. An average of 19 subjects were selected from each hospital at random. In all 115 blood samples were collected. About $4.0 \mathrm{~mL}$ of blood was taken from a subject. All the blood samples were collected and stored in a fridge $\left(2-4^{\circ} \mathrm{C}\right)$. The subjects were made to respond to a detailed questionnaire regarding dietary habits, gender, age, occupation etc. A total of 115 subjects responded to the questionnaire. This consists of 70 female and 45 male with $10 \%$ between the ages of $1-18$ years, $70 \%$ between the ages of 19-49 years and 20\% above 50 years. Most of the subjects were nursing and pregnant women who normally visit the hospital for their antenatal and postnatal care.

Control samples: The control blood samples were also taken from subjects at Akatsi and its environs in the Volta region on two occasions. The distance from Tarkwa to Akatsi is about $480 \mathrm{Km}$ by road, where there are no known mining or industrial activities.

The blood samples were collected at random from subjects at Abor Government Hospital, Akatsi Government Hospital, St. Paul's Clinic at Akatsi and coded CBm (m=1-50). About $4.0 \mathrm{~mL}$ of blood was taken from each subject. A total of 50 blood samples were collected from the control area. In all a total of 50 subjects (control group) responded to the same questionnaire administered at Tarkwa. This consists of 40 female and 10 male with $5 \%$ between the ages of 1-18 years, $75 \%$ between the ages of $19-49$ years and $20 \%$ above 50 years.

Sample preparation: About $1.0 \mathrm{~mL}$ of the blood sample was taken by calibrated eppendorf pipette and diluted to $100.0 \mathrm{~mL}$ using deionised distilled water. The mixture was acidified with $12.0 \mathrm{M}$ sulphuric acid drop by drop until the $\mathrm{pH}$ of the mixture dropped to $1.5-2.0$ for $\mathrm{Hg}$ extraction. About $20.0 \mathrm{~mL}$ of $0.02 \%$ dithizone $/ \mathrm{CHCl}_{3}$ mixture was added to the mixture in a conical flask and shaken. The mixture in the conical flask was allowed to stand for ten minutes. The whole mixture was then transferred to $250.0 \mathrm{~mL}$ separation funnel. The mixture was then extracted with $20.0 \mathrm{~mL}$ aliquot of $1.5 \%$ sodium thiosulphate $\left(\mathrm{Na}_{2} \mathrm{~S}_{2} \mathrm{O}_{3}\right)$ three times. The organic phase was then separated from the aqueous phase into a labelled beaker. The aqueous phase in the separation funnel was again extracted with $20.0 \mathrm{~mL}$ aliquots of dithizone/chloroform solution three times. The organic phases were combined while the aqueous phases were discarded. The organic layer was transferred to an already washed labelled sample bottle and left in fumehood for the organic phase to evaporate. This evaporation stage reduced the sample volume and concentrated the analytes of interest. Similarly, the same procedure was repeated for As extraction but at a $\mathrm{pH}$ range of 2-2.5. Five sub-samples of $100 \mathrm{mg}$ of each organic phase was weighed and put into $1.5 \mathrm{~mL}$ vial and heat sealed. The sealed vials were then packed into a bigger vial for irradiation.. 
Reference material: A certified standard hair reference material GBW 09101 was similarly prepared, weighed and heat sealed for irradiation. The same mass of combined $\mathrm{Hg}$ and $\mathrm{As}$ comparator standards were used as quality control to validate the analytical technique.

Sample irradiation and counting: Irradiation and counting of samples using the Ghana Research Reactor-1 facility at Kwabenya have been described (Nyarko, Akaho, \& SerforArmah, 2003). The packed blood samples, comparator standards and the certified reference hair material GBW 09101 were irradiated at the inner irradiation sites of the Reactor-1 facility, using a pneumatic transfer system for $1 \mathrm{hr}$. at a thermal neutron flux $5.1011 \mathrm{n} . \mathrm{cm} 2 \mathrm{~s}-1$ and a pressure of 1.723 bar

The counting of samples was done using a gamma-ray spectroscopy system. The system was made up of N-type HPGe detector model GR2518, and HV Power Supply Model 3103, a spectroscopy Amplifier Model 2020, an ACCUSPEC Multi-channel Analyzer (MCA) emulation software card, all manufactured by Canberra Industries, Inc, and 486 micro-computer. The efficiency of the detector was $25 \%$. Each sample was placed at a distance of $2.6 \mathrm{~cm}$ from the detector surface and counted. The accumulated spectra intensities were analyzed qualitatively and quantitatively. The qualitative analysis involved the identification of As using the $559.1 \mathrm{keV}$ of $76 \mathrm{As}$ and $\mathrm{Hg}$ using $77.3 \mathrm{keV}$ of $197 \mathrm{Hg}$. The quantitative analysis was done by converting the counts (area) under the photopeak of the radionuclides by comparator NAA method using comparator As and $\mathrm{Hg}$ standards (Nyarko, Akaho, \& Serfor-Armah, 2003). Cobalt-60 source was used to calibrate the detector whenever counting is going to be done.

Validation of analytical technique: Certified standard reference materials, human hair GBW 09101, was analysed periodically along side with the experimental and control samples to validate the analytical technique. The levels of the elements in the standard reference materials were in good agreement with the certified values as the Spearman's rank correlation coefficient was +0.99 for GBW 09101. The results of the field samples were within $\pm 4 \%$ of the certified value. The measurement precision specified by the relative standard deviation was within $\pm 3 \%$.

Data analysis procedure: An independent one- tailed student t-test was used to compare the means of both the experimental and the control groups. The level of probability at which significant differences existed between the groups was set at $p<0.05$ at $95 \%$ confidence level.

Table1 Trace element concentration $(\mu \mathrm{g} / \mathrm{g})$ of human hair standard reference material GBW 09101 with standard deviations, $n=5$

\begin{tabular}{lcc}
\hline Element & This work & Certified value \\
\hline As & $0.60 \pm 0.03$ & $0.59 \pm 0.07$
\end{tabular}


Levels of arsenic and mercury in human blood from Tarkwa and its environs, a mining area in

Wassa West District of Ghana Samlafo, B. V.Samlafo, B. V.

\begin{tabular}{lrr}
$\mathrm{Hg}$ & $2.10 \pm 0.05$ & $2.16 \pm 0.21$ \\
$\mathrm{Cu}$ & $22.50 \pm 1.6$ & $23.0 \pm 1.4$ \\
$\mathrm{Na}$ & $264.60 \pm 22$ & $266.0 \pm 12$ \\
$\mathrm{Mn}$ & $2.92 \pm 0.01$ & $2.94 \pm 0.2$ \\
$\mathrm{Ca}$ & $1091 \pm 81$ & $1090 \pm 72$ \\
\hline
\end{tabular}

\section{Results}

Mercury in blood samples in the experimental group (Table 2) ranged from 0.01- 0.70 $\mu \mathrm{g} / \mathrm{mL}$, with a mean of $0.08 \mu \mathrm{g} / \mathrm{mL}$. The standard deviation was 0.08 , and the relative standard deviation was $98.22 \%$. Mercury in the control subjects (Table3) ranged from $0.01-2.38) \mu \mathrm{g} / \mathrm{mL}$, with a mean of $0.12 \mu \mathrm{g} / \mathrm{mL}$. The standard deviation was 0.41 , and the relative standard deviation was $334.02 \%$. Mercury was found in all the experimental subjects. However, $\mathrm{Hg}$ was not detected in $66 \%$ of the control subjects. There was no statistical significant difference in the level of $\mathrm{Hg}$ in both the experimental and the control subject. Hence, the level of $\mathrm{Hg}$ in the experimental subjects could not be due to the mining activities in the area. The levels of $\mathrm{Hg}$ in both the experimental and control subjects could be from their dietary sources especially the consumption of fish. All the levels of $\mathrm{Hg}$ observed in the experimental and the control sample were below the recommended reference value of $5-10 \mu \mathrm{g} / \mathrm{L}$ set by the WHO (2004). However, the International Commission on Occupational Health and the International Union of Pure and Applied Chemistry Commission on Toxicology estimated that a mean value of 2.0 $\mu \mathrm{g} /$ litre as the background blood level of mercury in persons who do not eat fish (Nordberg, Brune, Gerhardsson, Grandjean, Vesterberg \& Wester, 1992). According to Nordberg et al., (1992), these levels are "background" in the sense that they represent the average levels in blood in the general population and are not associated with a particular source of mercury exposure. However, the intra- and inter individual differences in these biomarkers are substantial, possibly due to dental amalgam and ingestion of contaminated fish (IPCS, 1991). According to ATSDR (1999) available evidence indicates that the metabolism of all forms of inorganic $\mathrm{Hg}$ is similar for humans and laboratory mammals. Once absorbed, elemental and inorganic $\mathrm{Hg}$ enter an oxidation- reduction cycle. Elemental $\mathrm{Hg}$ is oxidized to the divalent inorganic cation in the red blood cells and lungs. Evidence from animal studies suggests the liver as an additional site of oxidation. Absorbed divalent cation from exposure to mercuric mercury compounds can, in turn, be reduced to the metallic or monovalent form and released as exhaled elemental mercury vapour (ATSDR, 1999). This and other reasons might be responsible for the low levels of $\mathrm{Hg}$ observed in both the control and experimental subjects. 
African Journal of Educational Studies in Mathematics and Sciences Vol. 8, 2010

Table 2: $\quad$ Mean concentrations of $\mathrm{As}$ and $\mathrm{Hg}$ in experimental blood samples with standard deviations ( $\mu \mathrm{gg} / \mathrm{mL}$ wet weight), $\mathrm{n}=5$

\begin{tabular}{lllllllllll}
\hline Element & $\mathrm{B} 1$ & $\mathrm{~B} 2$ & $\mathrm{~B} 3$ & $\mathrm{~B} 4$ & $\mathrm{~B} 5$ & $\mathrm{~B} 6$ & $\mathrm{~B} 7$ & $\mathrm{~B} 8$ & $\mathrm{~B} 9$ & $\mathrm{~B} 10$ \\
$\mathrm{As}$ & $0.86 \pm 0.13$ & $2.36 \pm 0.35$ & $0.43 \pm 0.06$ & $0.36 \pm 0.05$ & $1.37 \pm 0.21$ & $0.07 \pm 0.01$ & $0.28 \pm 0.04$ & $0.09 \pm 0.01$ & $0.19 \pm 0.02$ & $0.09 \pm 0.02$ \\
$\mathrm{Hg}$ & $0.04 \pm 0.01$ & $0.03 \pm 0.01$ & $0.09 \pm 0.01$ & $0.19 \pm 0.03$ & $0.13 \pm 0.02$ & $0.01 \pm 0$ & $0.02 \pm 0.01$ & $0.05 \pm 0.01$ & $0.02 \pm 0.01$ & $0.04 \pm 0.01$ \\
\hline Table 2: (continued) & & & & & & & & & & \\
Element & $\mathrm{B} 11$ & $\mathrm{~B} 12$ & $\mathrm{~B} 13$ & $\mathrm{~B} 14$ & $\mathrm{~B} 15$ & $\mathrm{~B} 16$ & $\mathrm{~B} 17$ & $\mathrm{~B} 18$ & $\mathrm{~B} 19$ & $\mathrm{~B} 20$ \\
As & $0.14 \pm 0.02$ & $0.04 \pm 0.01$ & $0.21 \pm 0.03$ & $0.08 \pm 0.01$ & $0.13 \pm 0.02$ & $0.04 \pm 0.01$ & $0.06 \pm 0.01$ & $0.12 \pm 0.02$ & $0.10 \pm 0.01$ & $0.15 \pm 0.02$ \\
$\mathrm{Hg}$ & $0.03 \pm 0.01$ & $0.05 \pm 0.02$ & $0.02 \pm 0.01$ & $0.04 \pm 0.01$ & $0.02 \pm 0.01$ & $0.03 \pm 0.01$ & $0.03 \pm 0.01$ & $0.05 \pm 0.01$ & $0.03 \pm 0.01$ & $0.05 \pm 0.01$ \\
\hline Table 2: (continued) & & & & & & & & & \\
Element & $\mathrm{B} 21$ & $\mathrm{~B} 22$ & $\mathrm{~B} 23$ & $\mathrm{~B} 24$ & $\mathrm{~B} 25$ & $\mathrm{~B} 26$ & $\mathrm{~B} 27$ & $\mathrm{~B} 28$ & $\mathrm{~B} 29$ & $\mathrm{~B} 30$ \\
As & $0.21 \pm 0.03$ & $0.09 \pm 0.01$ & $0.19 \pm 0.03$ & $0.13 \pm 0.02$ & $0.16 \pm 0.02$ & $0.10 \pm 0.01$ & $0.11 \pm 0.02$ & $0.05 \pm 0.01$ & $0.40 \pm 0.01$ & $0.09 \pm 0.02$ \\
Hg & $0.05 \pm 0.01$ & $0.07 \pm 0.02$ & $0.05 \pm 0.01$ & $0.05 \pm 0.01$ & $0.03 \pm 0.01$ & $0.04 \pm 0.01$ & $0.04 \pm 0.01$ & $0.11 \pm 0.02$ & $0.04 \pm 0.01$ & $0.10 \pm 0.01$ \\
\hline Table 2: (continued) & & & & & & & & & \\
Element & $\mathrm{B} 31$ & $\mathrm{~B} 32$ & $\mathrm{~B} 33$ & $\mathrm{~B} 34$ & $\mathrm{~B} 35$ & $\mathrm{~B} 36$ & $\mathrm{~B} 37$ & $\mathrm{~B} 38$ & $\mathrm{~B} 39$ & $\mathrm{~B} 40$ \\
As & $0.10 \pm 0.01$ & $0.08 \pm 0.01$ & $0.10 \pm 0.02$ & $0.05 \pm 0.01$ & $0.16 \pm 0.02$ & $0.09 \pm 0.01$ & $0.03 \pm 0.01$ & $0.16 \pm 0.01$ & $0.08 \pm 0.01$ & $0.20 \pm 0.03$ \\
Hg & $0.03 \pm 0.01$ & $0.04 \pm 0.01$ & $0.05 \pm 0.01$ & $0.03 \pm 0.01$ & $0.01 \pm 0$ & $0.05 \pm 0.01$ & $0.06 \pm 0.02$ & $0.07 \pm 0.01$ & $0.03 \pm 0.01$ & $0.01 \pm 0$ \\
\hline Table 2: (continued) & & & & & & & & & \\
Element & $\mathrm{B} 41$ & $\mathrm{~B} 42$ & $\mathrm{~B} 43$ & $\mathrm{~B} 44$ & $\mathrm{~B} 45$ & $\mathrm{~B} 46$ & $\mathrm{~B} 47$ & $\mathrm{~B} 48$ & $\mathrm{~B} 49$ & $\mathrm{~B} 50$ \\
As & $0.20 \pm 0.03$ & $0.52 \pm 0.07$ & $0.33 \pm 0.05$ & $0.16 \pm 0.02$ & $0.11 \pm 0.02$ & $0.24 \pm 0.02$ & $0.26 \pm 0.04$ & $0.15 \pm 0.02$ & $0.35 \pm 0.05$ & $2.84 \pm 0.42$ \\
Hg & $0.09 \pm 0.01$ & $0.11 \pm 0.02$ & $0.07 \pm 0.01$ & $0.12 \pm 0.01$ & $0.01 \pm 0$ & $0.09 \pm 0.01$ & $0.07 \pm 0.01$ & $0.11 \pm 0.02$ & $0.09 \pm 0.01$ & $0.22 \pm 0.03$ \\
\hline \multicolumn{2}{l}{ Table 2: (continued) } & & & & & & & & & \\
Element & $\mathrm{B} 51$ & $\mathrm{~B} 52$ & $\mathrm{~B} 53$ & $\mathrm{~B} 54$ & $\mathrm{~B} 55$ & $\mathrm{~B} 56$ & $\mathrm{~B} 57$ & $\mathrm{~B} 58$ & $\mathrm{~B} 59$ & $\mathrm{~B} 60$ \\
As & $0.22 \pm 0.03$ & $0.33 \pm 0.05$ & $0.34 \pm 0.05$ & $0.98 \pm 0.15$ & $0.68 \pm 0.01$ & $0.27 \pm 0.04$ & $0.26 \pm 0.04$ & $0.39 \pm 0.05$ & $0.51 \pm 0.08$ & $0.30 \pm 0.05$
\end{tabular}


Levels of arsenic and mercury in human blood from Tarkwa and its environs, a mining area in Wassa West District of Ghana Samlafo, B. V.Samlafo, B. V.

\begin{tabular}{lllllllllll}
$\mathrm{Hg}$ & $0.10 \pm 0.02$ & $0.03 \pm 0.01$ & $0.07 \pm 0.01$ & $0.06 \pm 0.01$ & $0.08 \pm 0.01$ & $0.05 \pm 0.01$ & $0.07 \pm 0.01$ & $0.03 \pm 0.01$ & $0.12 \pm 0.02$ & $0.10 \pm 0.01$ \\
\hline Table 2: (continued) & & & & & & & & & & \\
Element & $\mathrm{B} 61$ & $\mathrm{~B} 62$ & $\mathrm{~B} 63$ & $\mathrm{~B} 64$ & $\mathrm{~B} 65$ & $\mathrm{~B} 66$ & $\mathrm{~B} 67$ & $\mathrm{~B} 68$ & $\mathrm{~B} 69$ & $\mathrm{~B} 70$ \\
$\mathrm{As}$ & $0.38 \pm 0.06$ & $0.41 \pm 0.06$ & $0.33 \pm 0.05$ & $0.29 \pm 0.04$ & $5.82 \pm 0.87$ & $0.85 \pm 0.13$ & $2.82 \pm 0.42$ & $1.86 \pm 0.27$ & $2.95 \pm 0.44$ & $2.98 \pm 0.45$ \\
$\mathrm{Hg}$ & $0.22 \pm 0.03$ & $0.14 \pm 0.02$ & $0.02 \pm 0.01$ & $0.15 \pm 0.02$ & $0.09 \pm 0.01$ & $0.06 \pm 0.01$ & $0.13 \pm 0.02$ & $0.09 \pm 0.01$ & $0.05 \pm 0.01$ & $0.01 \pm 0$ \\
\hline
\end{tabular}


Table 2: $\quad$ Mean concentrations of As and $\mathrm{Hg}$ in experimental blood samples with standard deviations ( $(\mu \mathrm{g} / \mathrm{mL}$ wet weight), $\mathrm{n}=5$ (continued)

\begin{tabular}{|c|c|c|c|c|c|c|c|c|c|c|}
\hline \multicolumn{11}{|c|}{ Table 2: (continued) } \\
\hline Element & B71 & B72 & B73 & B74 & B75 & B76 & B77 & B78 & B79 & B80 \\
\hline As & $1.97 \pm 0.29$ & $1.92 \pm 0.28$ & $2.34 \pm 0.35$ & $2.07 \pm 0.31$ & $2.66 \pm 0.40$ & $1.36 \pm 0.20$ & $3.44 \pm 0.52$ & $3.32 \pm 0.50$ & $0.27 \pm 0.04$ & $0.12 \pm 0.02$ \\
\hline $\mathrm{Hg}$ & $0.01 \pm 0$ & $0.09 \pm 0.01$ & $0.11 \pm 0.02$ & $0.21 \pm 0.03$ & $0.10 \pm 0.01$ & $0.04 \pm 0.01$ & $0.02 \pm 0.01$ & $0.05 \pm 0.01$ & $0.04 \pm 0.01$ & $0.12 \pm 0.02$ \\
\hline \multicolumn{11}{|c|}{ Table 2: (continued) } \\
\hline Element & B81 & B82 & B83 & B84 & B85 & B86 & B87 & B88 & B89 & B90 \\
\hline As & $0.03 \pm 0.01$ & $0.02 \pm 0.01$ & $0.04 \pm 0.01$ & $0.12 \pm 0.01$ & $0.41 \pm 0.08$ & $0.42 \pm 0.20$ & $0.41 \pm 0.10$ & $0.33 \pm 0.10$ & $0.02 \pm 0.01$ & $0.64 \pm 0.20$ \\
\hline $\mathrm{Hg}$ & $0.03 \pm 0.01$ & $0.02 \pm 0.01$ & $0.03 \pm 0.01$ & $0.01 \pm 0$ & $0.17 \pm 0.02$ & $0.11 \pm 0.02$ & $0.17 \pm 0.03$ & $0.16 \pm 0.02$ & $0.01 \pm 0$ & $0.15 \pm 0.02$ \\
\hline
\end{tabular}

Table 2: (continued) Mean concentrations of $\mathrm{As}$ and $\mathrm{Hg}$ in experimental blood samples with standard deviations ( $\mu \mathrm{g} / \mathrm{mL}$ wet weight), $\mathrm{n}=5$

\begin{tabular}{lllllllllll} 
Element & B91 & B92 & B93 & B94 & B95 & B96 & B97 & B98 & B99 & B100 \\
As & $0.58 \pm 0.06$ & $0.67 \pm 0.23$ & $0.21 \pm 0.10$ & $0.29 \pm 0.10$ & $0.30 \pm 0.08$ & $0.28 \pm 0.07$ & $0.36 \pm 0.06$ & $2.80 \pm 0.27$ & $0.62 \pm 0.20$ & $0.35 \pm 0.08$ \\
$\mathrm{Hg}$ & $0.07 \pm 0.01$ & $0.13 \pm 0.02$ & $0.06 \pm 0.01$ & $0.09 \pm 0.01$ & $0.12 \pm 0.02$ & $0.11 \pm 0.02$ & $0.02 \pm 0.01$ & $0.06 \pm 0.01$ & $0.70 \pm 0.01$ & $0.08 \pm 0.01$ \\
\hline
\end{tabular}

Table 2: (continued) Mean concentrations of $\mathrm{As}$ and $\mathrm{Hg}$ in experimental blood samples with standard deviations ( $\mu \mathrm{g} / \mathrm{mL}$ wet weight), $\mathrm{n}=5$

$\begin{array}{lllllllllll}\text { Element } & \mathrm{B} 101 & \mathrm{~B} 102 & \mathrm{~B} 103 & \mathrm{~B} 104 & \mathrm{~B} 105 & \mathrm{~B} 106 & \mathrm{~B} 107 & \mathrm{~B} 108 & \mathrm{~B} 109 \\ \mathrm{As} & 0.17 \pm 0.05 & 0.22 \pm 0.06 & 0.16 \pm 0.02 & 0.18 \pm 0.06 & 0.91 \pm 0.07 & 0.16 \pm 0.08 & 0.14 \pm 0.01 & 0.31 \pm 0.04 & 0.48 \pm 0.01 & 0.45 \pm 0.04 \\ \mathrm{Hg} & 0.13 \pm 0.02 & 0.07 \pm 0.01 & 0.05 \pm 0.01 & 0.10 \pm 0.02 & 0.05 \pm 0.01 & 0.02 \pm 0 & 0.07 \pm 0.01 & 0.08 \pm 0.01 & 0.05 \pm 0.01 & 0.06 \pm 0.01\end{array}$


Levels of arsenic and mercury in human blood from Tarkwa and its environs, a mining area in Wassa West District of Ghana Samlafo, B. V.Samlafo, B. V.

\begin{tabular}{llllll}
\multicolumn{5}{l}{ Table 2: (continued) Mean concentrations of As and $\mathrm{Hg}$ in experimental blood samples with standard deviations $(\mu \mathrm{g} / \mathrm{mL}$ wet weight), $\mathrm{n}=5$} \\
Element & $\mathrm{B} 111$ & $\mathrm{~B} 112$ & $\mathrm{~B} 113$ & $\mathrm{~B} 114$ & $\mathrm{~B} 115$ \\
As & $0.50 \pm 0.05$ & $2.34 \pm 0.54$ & $3.14 \pm 0.72$ & $1.29 \pm 0.21$ & $0.49 \pm 0.10$ \\
$\mathrm{Hg}$ & $0.10 \pm 0.01$ & $0.10 \pm 0.01$ & $0.08 \pm 0.02$ & $0.09 \pm 0.01$ & $0.12 \pm 0.02$ \\
\hline
\end{tabular}

$\mathrm{ND}=$ Not Detected 
African Journal of Educational Studies in Mathematics and Sciences Vol. 8, 2010 
Table 3 Mean concentrations of As and $\mathrm{Hg}$ in control blood samples with standard deviations $(\mu \mathrm{g} / \mathrm{mL}$ wet weight), $\mathrm{n}=5$

\begin{tabular}{|c|c|c|c|c|c|c|c|c|c|c|}
\hline Element & CB1 & CB2 & CB3 & CB4 & CB5 & CB6 & CB7 & CB8 & CB9 & CB10 \\
\hline As & $0.18 \pm 0.01$ & ND & $0.13 \pm 0.02$ & $0.27 \pm 0.01$ & ND & $0.22 \pm 0.01$ & $0.37 \pm 0.02$ & $0.13 \pm 0.01$ & ND & ND \\
\hline $\mathrm{Hg}$ & $0.07 \pm 0.01$ & ND & ND & ND & ND & ND & $0.76 \pm 0.10$ & $0.26 \pm 0.08$ & $1.53 \pm 0.20$ & ND \\
\hline \multicolumn{11}{|c|}{ Table 3 : (continued) } \\
\hline Element & CB11 & CB12 & CB13 & CB14 & CB15 & CB16 & CB17 & CB18 & CB19 & CB20 \\
\hline As & ND & ND & ND & ND & ND & $0.04 \pm 0.01$ & ND & $0.05 \pm 0.01$ & ND & ND \\
\hline $\mathrm{Hg}$ & ND & ND & ND & $2.38 \pm 0.25$ & ND & $0.63 \pm 0.12$ & ND & ND & ND & ND \\
\hline \multicolumn{11}{|c|}{ Table 3 : (continued) } \\
\hline Element & CB21 & CB22 & CB23 & CB24 & CB25 & CB26 & CB27 & CB28 & CB29 & CB30 \\
\hline As & $0.14 \pm 0.02$ & $0.08 \pm 0.02$ & ND & ND & ND & $0.04 \pm 0.01$ & $0.02 \pm 0.01$ & ND & ND & $0.06 \pm 0.02$ \\
\hline $\mathrm{Hg}$ & ND & ND & ND & ND & $0.8 \pm 0.01$ & $0.05 \pm 0.02$ & $0.04 \pm 0.01$ & ND & ND & ND \\
\hline \multicolumn{11}{|c|}{ Table 3 : (continued) } \\
\hline Element & CB31 & CB32 & CB33 & CB34 & CB35 & CB36 & CB37 & CB38 & CB39 & CB40 \\
\hline As & $0.04 \pm 0.01$ & ND & $0.08 \pm 0.01$ & ND & ND & $0.06 \pm 0.02$ & $0.02 \pm 0.01$ & ND & ND & ND \\
\hline $\mathrm{Hg}$ & $0.09 \pm 0.01$ & ND & $0.06 \pm 0.01$ & ND & ND & $0.02 \pm 0.01$ & $0.08 \pm 0.01$ & ND & ND & ND \\
\hline \multicolumn{11}{|c|}{ Table 3 : (continued) } \\
\hline Element & CB41 & CB42 & CB43 & CB44 & CB45 & CB46 & CB47 & CB48 & CB49 & CB50 \\
\hline As & $0.06 \pm 0.01$ & ND & $0.02 \pm 0.01$ & $0.01 \pm 0$ & ND & ND & ND & $0.04 \pm 0.01$ & $0.01 \pm 0$ & ND \\
\hline $\mathrm{Hg}$ & $0.05 \pm 0.01$ & $0.01 \pm 0$ & ND & ND & ND & $0.04 \pm 0.01$ & $0.02 \pm 0.01$ & ND & ND & ND \\
\hline
\end{tabular}

$\mathrm{ND}=$ Not Detected 
Arsenic levels in blood in the experimental subjects (see Table 2) ranged from 0.02$5.82 \mu \mathrm{g} / \mathrm{mL}$, with a mean of $0.67 \mu \mathrm{g} / \mathrm{mL}$. The standard deviation was 0.99 and the relative standard deviation was $147.33 \%$. The levels of As in the control subjects (see Table 3) ranged from 0.01-0.37 with a mean of $0.04 \mu \mathrm{g} / \mathrm{mL}$. The standard deviation was 0.08 and the relative standard deviation was $186.53 \%$. Arsenic was detected in all experimental subjects. However, As was not detected in 52\% of the control subjects. There was statistical differences between the levels observed in the experimental samples and that of the control group $\left(\mathrm{p}=6.71 \times 10^{-6}>0.05\right)$. This implied that the level observed in the experimental group could be due to the mining activities in the area.

Since water is the most common source of As exposure, the levels observed in the experimental subjects could be due to the use of contaminated water in their domestic activities. Blood is the main vehicle for the transport of arsenic following absorption, and arsenic is cleared relatively rapidly from it. Arsenic movement from the blood appears to conform to a three-compartment model, which must reflect in part the biomethylation of inorganic arsenic. Arsenic disappears rapidly from blood, so measurements in blood only tell you about recent high exposures, such as poisonings, or long-term exposures. Transplacental transfer of arsenic appear to occur in humans. This finding is based on autopsy data and on reports showing that blood levels in the cords of neonates approximate those of their mothers (7). Data on the effects of valency and exposure level on the tissue distribution of arsenic indicate that levels of arsenic in the kidneys, liver, bile, brain, skeleton, skin and blood are 2-25 times higher for the trivalent than for the pentavalent form and are greatly increased at higher doses (13).

\section{Conclusion}

There was no statistical significant difference in the level of $\mathrm{Hg}$ in both the experimental and the control subject. Hence, the level of $\mathrm{Hg}$ in the experimental subjects could not be due to the mining activities in the area. There was statistical differences between the levels observed in the experimental samples and that of the control group $\left(p=6.71 \times 10^{-6}>0.05\right)$. This implied that the level observed in the experimental group could be due to the mining activities in the area.

\section{References}

ATSDR (1999). Toxicological profile for mercury (update). Atlanta, GA, US Department of Health and Human Services, Public Health Service, Agency for Toxic Substances and Disease Registry, March, pp15-68.

Eto, K., Tokunaga, Y., Nagashima, K., Takeuchi, T. (2002). An autopsy case of Minamata disease(Methylmercury poisoning)-Pathological viewpoints of peripheral nerves. Toxicologic Pathology. 30 (6): 714-722.

Fukuda, Y., Ushijama, K., Kitano, T., Sakamoto, M. and Futatsuka, M. (1999). An Analysis of Subjective Complaints in a Population Living in a Methylmercury-Polluted Area. Environmental Research Section. 81(2): 100107.

Grandjean, P., Weihe, P., White, R.F., Debes, F., Araki, S., Yokoyama, K., Murata, K., Sorensen, N., Dahl, R.,Jorgensen, P.J. (1997): Cognitive deficit in 7-yearold children with prenatal exposure to methylmercury, Neurotoxicology and Teratology 19 (6): 417-428. 
US Environmental Protection Agency, (1984). Health assessment document for inorganic arsenic. (Final report, No. EPA-600/8-83-021F) Park, NC: Research Triangle. p. 351.

IPCS (1991). Inorganic mercury. International Programme on Chemical Safety (Environmental Health Criteria 118). Geneva, Switzerland: World Health Organization. pp20-60.

Kinjo, Y., Higashi, H., Nakano, A., Sakamoto, M., Sakai, R. (1993). Profile of Subjective Complaints and Activities of Daily Living among Current Patients with Minamata disease after 3 Decades. Environmental Research 63 (2): 241251 .

LaKind, J.S., et al. (2005): Human milk biomonitoring data: interpretation and risk assessment issues. Journal of Toxicology and Environmental Health Part A. 68: 1713-1769.

National Research Council (NRC). (2000). Toxicological Effects of Methylmercury. Washington, DC: National Academy Press, pp 5-20.

Nordberg GF, Brune D, Gerhardsson L, Grandjean P, Vesterberg O, Wester PO (1992) The ICOH and IUPAC international programme for establishing reference values of metals. The Science of the Total Environment, 120(12):17-21.

Nyarko B.J.B., Akaho E.H.K., and Serfor-Armah Y., (2003). Application of NAA Standardization methods using a low power research rector, J. Radioanal, Nucl. Chem. Vo. 257, 2003, pp. 361-366.

Sakamoto, M., Kubota, M., Liu, X.J., Murata, K., Nakai, K., Satoh, H. (2004). Maternal and foetal mercury and n-3 polyunsaturated fatty acids as a risk and benefit of fish consumption to foetus. Environmental Science and Technology. 38 (14): 3860-3863.

Serfor-Armah Y, Samlafo B.V and Yeaboah P.O, Arsenic and Mercury levels in human hair and nail from gold mining areas in the Wassa West District of Ghana, Journal Applied Science and Technology, Vol.14 Nos. 1\&2 2009 pp111-116.

United Nations Environment Programme (UNEP). (2002): Global Mercury Assessment. UNEP Chemicals Mercury Programme, Geneva, Switzerland pp $2-50$.

United Nations Industrial Development Organization (UNIDO). (2003). Removal of Barriers to Introduction of Cleaner Artisanal Gold Mining and Extraction Technologie, pp 5-45.

WHO (1981). Arsenic, International Programme on Chemical Safety (Environmental Health Criteria 18). Geneva, Switzerland: World Health Organization, pp 2387.

WHO, IPCS, (2001). Arsenic and Arsenic compounds Environmental Health criteria 224, Geneva, 2001, pp 10-50

World Health Organization (WHO) (2004): Technical Report Series 922. Sixty-first report of the Joint FAO/WHO Expert Committee on Food Additives (JEFCA), 2004, pp. 133. 
African Journal of Educational Studies in Mathematics and Sciences Vol. 8, 2010 